\title{
Francisco de los Cobos y la fama: promoción arquitectónica y literatura cortesana de oposición ${ }^{1}$
}

\author{
Sergio RAMIRO RAMÍREZ \\ Universidad Complutense de Madrid \\ Programa de doctorado en Historia Contemporánea \\ Departamento de Historia Contemporánea \\ serramir@estumail.ucm.es
}

Entregado: 3/12/2012

Aceptado: 9/5/2013

\section{RESUMEN}

En este artículo nos proponemos analizar la fama personal de Francisco de los Cobos ligada a sus promociones edilicias, en especial la de la Sacra Capilla de El Salvador de Úbeda, tomando como referencia testimonios directos sobre su persona tanto en vida como en los años inmediatamente posteriores a su muerte. Prestaremos una especial atención a obras impresas como el Aviso de privados y doctrina de cortesanos del obispo de Mondoñedo Fray Antonio de Guevara (1480-1545) o el Diálogo de la preparación de la muerte de Pedro de Navarra (ca. 1504-1567), las cuales aluden directamente a nuestro personaje. Estos testimonios nos permitirán hacernos una idea de la fama de la que gozaban las obras de Cobos en su época al tiempo que constatarán como la Sacra Capilla de El Salvador fue usada por sus detractores como excusa para infamar a Cobos en un contexto de luchas intestinas por conseguir la supremacía en la corte y la política del imperio de Carlos V.

Palabras clave: Francisco de los Cobos, fama, promoción arquitectónica, Sacra Capilla de El Salvador, literatura.

\section{Francisco de los Cobos and the fame: architectural promotion and the opposition courtly literature}

\begin{abstract}
In this article we set out to analyze Francisco de los Cobos' personal fame related to his architectural promotions, especially the Holy Chapel of the Saviour in Úbeda, with reference to contemporary testimonies about his personality during his life and in the immediately following years after his death. We will pay special attention to printed works as Aviso de privados y doctrina de cortesanos by the bishop of Mondoñedo Fray Antonio de Guevara (1480-1545) or Diálogos de la preparación de la muerte by

1 Este artículo forma parte de la investigación en curso Francisco de los Cobos y Molina (1477-1547) y las artes que busca culminar en una tesis doctoral del mismo título en el programa de doctorado de Historia Contemporánea de la Universidad Complutense de Madrid y bajo la dirección de la doctora $\mathrm{M}^{\mathrm{a}}$ Ángeles Toajas Roger, catedrática del Departamento de Historia del Arte II (Moderno) de la Universidad Complutense y la codirección del doctor Pedro Antonio Galera Andreu, catedrático del Departamento de Patrimonio Histórico de la Universidad de Jaén.
\end{abstract}


Pedro de Navarra (ca. 1504-1567), that directly allude to our personage. These testimonies will allow us to have an idea of the fame Cobos' buildings had in his time. In addition they will prove how the Holy Chapel of the Saviour was used by his detractors as an excuse to defame Cobos in the context of the internal fights to reach the supremacy in the Emperor Charles V's court.

Key words: Francisco de los Cobos, fame, architectural promotion, Holy Chapel of the Saviour, literature.

En la primera mitad del siglo XVI, el nombre de Francisco de los Cobos recorrió los territorios del mundo conocido como el de uno de los hombres más poderosos de su tiempo. Entre otros cargos, mercedes reales y posesiones, Cobos acumuló en su persona los títulos de Comendador Mayor de los Bastimentos de León de la Orden de Santiago, Adelantado Mayor de Cazorla o señor de Torres, Canena, Sabiote y Velliza. Pero ciertamente fue más reconocido por el título oficioso de "privado" debido a su cargo como consejero del Emperador, nombrado para tal por el Monarca junto a Nicolás Perrenot de Granvela (1484-1550) tras la muerte del Gran Canciller Mercurino Gattinara en $1530^{2}$. Algunos testimonios de la tercera década del siglo XVI son muy esclarecedores de su posición privilegiada, así Martín de Salinas refería al secretario Castillejo en carta fechada en Valladolid a 20 de junio de 1533: "El Comendador Mayor Cobos es, según dicen, muy favorecido de Su Magestad y ansí lo creen en todo este reino, porque dicen que es mucha parte y para lo ser más y que todo está debaxo de su mandamiento y sabiduría [...] Acá espántase las gentes de su poder y según sus habilidad y bondad de todo es merecedor" ${ }^{3} \mathrm{o}$ de una forma más poética escribe Pietro Aretino en 1535 que Cobos "tien la chiave del secreto animo de l'imperatore"4

Estos extractos escogidos muestran la omnipresencia de Cobos en las decisiones tomadas por Carlos V, sobre todo en asuntos hacendísticos, donde se instituye como un auténtico experto; a lo que debemos sumar su capacidad para las tareas diplomáticas de la que da buena cuenta el depósito de cartas personales que custodia el Archivo General de Simancas, la mayoría de ellas de asuntos de gobierno ${ }^{5}$. El estudio de su persona es inseparable de la de Carlos V desde el momento que vino a su encuentro en Flandes allá por 1516 cuando el futuro Emperador era aún príncipe. A partir de ahí destacará por ser el más entendido en los asuntos de Castilla, controlando el gobierno efectivo del reino durante más de veinte años ${ }^{6}$. Desde noviembre de 1539 -ante la

2 Keniston, H., Francisco de los Cobos: Secretario de Carlos V, Madrid, Castalia, 1980, pp. 138-139.

3 Rodríguez Villa, A., El Emperador Carlos V y su corte según las cartas de don Martín de Salinas, Madrid, Real Academia de la Historia, 1903-1905, pp. 231-232.

4 Citado en Álvarez Oller, Ma. T., "Francisco de los Cobos: su gusto y mecenazgo", Moreno Mendoza, A. (coord.), Francisco de los Cobos y su época, Madrid, Electa, 1997, p. 40.

5 Sánchez González, A., "La documentación patrimonial del secretario de Carlos V", Moreno Mendoza, Francisco de los Cobos... op. cit., p. 69. Esta ingente cantidad de cartas ha permitido también documentar la presencia de Cobos en asuntos artísticos de relevancia como es el comienzo de la carrera de Tiziano como pintor al servicio de la corte Habsburgo en Mancini, M., Tiziano e le corti d'Asburgo nei documenti degli archivi spagnoli, Venezia, Istituto Veneto de Scienze, Lettere ed Arti, 1998.

6 Elliot, J., La España Imperial, 1469-1716, Barcelona, Vicens Vives, 1989, p. 174. 
muerte de la Emperatriz Isabel en mayo de ese mismo año- hasta su propio fallecimiento en 1547, permanecerá en Castilla controlando el poder de los asuntos internos junto al cardenal Tavera, al tiempo que formó parte de los preceptores del príncipe Felipe en compañía del mismo cardenal y el duque de Alba. Es en estos años cuando da un definitivo impulso a la edificación de su fundación más personal, la Sacra Capilla de El Salvador, iglesia panteón donde aún hoy descansan sus restos y los de su mujer María de Mendoza.

La historiografía coincide actualmente en dibujar un Francisco de los Cobos astuto, trabajador, ambicioso y poseedor de una gran capacidad para prever la salida más ventajosa en las encrucijadas y oportunidades de cambio que brindaba el paso de la monarquía autoritaria de los Reyes Católicos a la reconstitución de una máquina imperial que no tenía parangón en occidente desde el Imperio Romano. Es a través de esta participación en el nuevo gigante burocrático por lo que conseguirá ascender desde su posición familiar como hijo de un hidalgo ubetense a Consejero de Estado del mayor monarca de su época. En este camino no exento de elecciones, luchas intestinas dentro de la Corte por ganar el favor del Emperador y demás actividades políticas de su época, utilizará la promoción artística como medio legitimador de la nueva casa dinástica que estaba fundando, al tiempo que conformará una imagen de hombre virtuoso merecedor de su posición gracias a su fidelidad al Emperador. Esta es, en definitiva, la historia de un hombre que testimonia con su existencia la convivencia del "otoño de la Edad Media" y la nueva cosmovisión del pensamiento renacentista.

\title{
La literatura de oposición y la infamia tras la muerte
}

\author{
"Mostró mucho que le pesaua morir, \\ y no creía su muerte, \\ por lo qual murió no con buena fama.' \\ López de Gomara, Anales del Emperador Carlos $V$.
}

Es lógico que el poder de Cobos no solo encontrase alabanzas de aquellos que querían ganar su favor, sino que también despertase en su tiempo envidias y recelos, tanto fundados como creados, en el juego político de la intriga cortesana. En los últimos años de la vida del Comendador parecen recrudecerse las conspiraciones y maledicencias contra nuestro personaje aprovechando seguramente la edad avanzada del privado, la soledad de Felipe II en Castilla tras la muerte de su madre la Emperatriz y la lejanía de Carlos V empleado a fondo en los asuntos imperiales. Pero sobre todo, las diatribas contra el Comendador se harán evidentes tras la muerte de este, una vez que no podía defenderse utilizando su influencia ante el monarca. El mejor testimonio de ello en vida del Comendador son, sin duda, las Instrucciones Secretas de Palamós, redactadas en mayo de 1543 por Carlos V para su hijo Felipe en esta ciudad cercana a la frontera francesa. El Emperador envía una serie de consejos secretos al heredero ante la posibilidad de perecer en la enésima guerra con Francia y, entre todas las advertencias, está incluida una amplia referencia al trato que debía guardar con Cobos, el cortesano al que dedica una mayor extensión en su misiva: "Cobos tengo 
por fiel, hasta ahora ha tenido poca pasión, ahora paréceme que no le falta, no es tan gran trabajador como solía. La edad y dolencia lo causan, bien creo que la mujer le fatiga, y es causa de meterle en la pasiones y aun no deja de darle mala fama cuanto al tomar, aunque creo que no toma él cosa de importancia, basta que unos presentes pequeños que hacen a su mujer le infame". Estas son opiniones del propio Monarca que refrendan los últimos años de debilidad política de Cobos cuya honra va cediendo ante los rumores cortesanos: "Bien será que os sirváis de él como yo lo hago, no a solas ni dándole mas autoridad que por la que por las instrucciones está contenido, mas, siguiendo aquellas, favorecedle, pues me ha servido y creo que hartos, querrían lo contrario, lo cual no merece ni conviene" 7 .

Cuatro años después, en mayo de 1547, Cobos muere en su palacio de Úbeda y López de Gomara, en sus Anales del Emperador Carlos V, dedica una escueta nota al óbito en la que carga con su pluma contra los excesos del privado del Emperador. Entre otras calificaciones, Gomara retrata a un hombre ambicioso y sin escrúpulos, un personaje codicioso, avaro y mujeriego que controló durante muchos años los asuntos del gobierno de España, Indias e Italia, colocando a su antojo a personas de su confianza aunque no tuvieran el suficiente mérito: "por lo qual fué de muchos notado y maldito" ${ }^{8}$. En definitiva, un cortesano disoluto y apegado a las tentaciones de la materialidad que temía a la muerte y que se granjeó una gran cantidad de enemigos por su venalidad y por deshacerse de todos aquellos que le estorbaron en el camino.

Sumado a este hecho, estaba la cuestión de su nacimiento humilde, el cual procuró también críticas contra nuestro personaje. Manifestaciones que se hicieron explícitas también tras su muerte, como es el caso de Gonzalo Fernández de Oviedo quien ironiza sobre su búsqueda ansiosa por el reconocimiento de nobleza para potenciar e instituir un nuevo linaje y así poder compararse con los grandes. Para ello no dudó en concertar los matrimonios de sus hijos -según Fernández de Oviedo- no por la dote que pudiera recoger a cambio -ya que don Francisco ya poseía una de las mayores rentas de su tiempo- sino por los títulos que reportaban a sus descendientes. Su hijo Diego de los Cobos obtuvo el título de marqués al casar con doña Francisca de Luna, marquesa de Camarasa así como baronesa de Ricla, Villaheliche y Alhamen. Por su parte, su hija María Sarmiento casó nada menos que con el duque de Sesa y nieto del Gran Capitán, Gonzalo Fernández de Córdoba. Fernández de Oviedo aprovecha asimismo para cargar contra la ambición desorbitada de Cobos a pesar de provenir de una parentela humilde:

SERENO: "Pues vos y yo le vimos tan pobre destos bienes de fortuna que no tenía nadasino la ventura que atendía. Y ésta le sucedió a él tal que tuuo más que otros e fue muy próspero e murió Señor e con todos esos títulos que avés dicho. E todos ellos no bastaron e le dar una ora de vida quando Dios le llamó E en verdad, todo cupo de su persona, e estuuo tan señor e encumbrado en su priuança que me paresçe que su hijo pudiera casar con mujer de más estado e rrenta, puesto que por su sangre es illustre."

\footnotetext{
7 Fernández Álvarez, M., Corpus documental de Carlos V, t. II, Salamanca, Universidad, 1975, p. 110. El subrayado es nuestro.

8 López de Gomara, F., Anales del Emperador Carlos V, edición inglesa de Merriman, R.B., Annals of the Emperor Charles V, Oxford, Clarendon Press, 1912, p. 225
} 
ALCAIDE: “Aunque otra señora con quien casara don Diego de los Couos truxera cinquenta o sesenta cuentos en dineros, no fuera tal su dote como el que truxo la señora de Camarasa doña Francisca de Luna, porque como dicho es, demás del Marquesado es señora de las varonías de Rricla e Villaheliche e Alhamen..."9

La carrera política de Cobos parece no estar exenta de confrontaciones con el resto de secretarios y prohombres de los consejos imperiales, al mismo tiempo que el favorecimiento a sus "criaturas" -en una estrategia lógica de control de la burocratizada corte imperial- ayudaba a soliviantar a aquellos que se sentían desplazados del poder por hombres cuyos méritos se medían en función de su fidelidad al Comendador. Quizás el conflicto más reconocido sea el que le enfrentó con el Gran Canciller Mercurino Gattinara, quien desde 1523 sostuvo una actitud de reproche ante la competencia que ejercían los secretarios reales ${ }^{10}$. Según Keniston, Gattinara acusaba a Cobos -a pesar de que aquel no mencionaba a ningún secretario en particular- en las peticiones enviadas en marzo de 1527 al monarca rogando su favor y la limitación de las prerrogativas de los consejos y secretarios. Para el hispanista americano en esta contienda salió victorioso Cobos, constituyendo el comienzo de la disminución de la influencia de Gattinara sobre las decisiones del Emperador ${ }^{11}$.

A pesar de esta victoria momentánea, con el fallecimiento de Gattinara en 1530 no parece terminar el enfrentamiento entre estos dos "partidos" con una idea muy diferente de la política imperial. De un lado, la historiografía ha esbozado la existencia de un ideario político imperialista, representado en un primer momento por la figura del Gran Canciller junto a erasmistas como Valdés, Vives o el mismo Erasmo. Por el contrario, otras propuestas pretendían conjugar las distintas realidades políticas e instituciones de los diferentes reinos ${ }^{12}$. En esta última facción se engloba la supuesta desafección de Cobos por la idea de Imperio ${ }^{13}$. Los integrantes de esta última línea política se reconocen también por sustentar una posición de defensa ante las ideas de renovación religiosa del humanismo cristiano de Erasmo y por una ortodoxia católica que desembocaría en la convocatoria del Concilio de Trento. Los seguidores de la primera facción siempre fueron sospechosos a ojos del Santo Oficio por estar demasiado cerca del evangelismo y la espiritualidad de la Reforma. A medida que la brecha entre

9 Fernández de Oviedo, G., Batallas y Quinquagenas, [Ms]1535-1556, edición de Bautista Avalle-Arce, J., Salamanca, Diputación, 1989, p. 120.

10 Elliot, La España Imperial... op. cit., p. 175.

11 Keniston, H., Francisco de los Cobos... op. cit., pp. 96 y ss. Por el contrario, Manuel Rivero Rodríguez opina que este conflicto nunca se dio siendo Keniston quien exageró la controversia al desarrollar un planteamiento consistente en ensalzar la figura de Cobos. Es más, para Rivero Rodríguez, Cobos y Gattinara debieron profesarse simpatía y amistad como demuestra que Cobos protegió a las hechuras del Gran Canciller, como Alfonso de Valdés, tras su muerte en 1530, Rivero Rodríguez, M. "Alfonso de Valdés y el Gran Canciller Mercurino Arborio di Gattinara: El erasmismo en la Cancillería imperial (1527-1530)”, e-Spania [En línea], 13 de junio 2012, en línea desde el 18 de junio de 2012, consultado el 13 de febrero 2013. URL: http://espania.revues.org/21322; DOI: 10.4000/e-spania.21322.

12 Checa Cremades, F., "Imperio universal y monarquía católica", Rosental, E.E., Arquitectura Imperial, Actas del Seminario sobre Arquitectura Imperial de la Universidad de Granada (Granada, 1986), Granada, Universidad, 1988, p. 15.

13 Keniston, Francisco de los Cobos... op. cit., p. 171. 
la Europa católica y la protestante se ahondaba, el partido de la ortodoxia, encabezado por Francisco de los Cobos y Juan Tavera arrinconaban al otro partido quienes pasaron a formalizar una especie de oposición con la espada de Damocles continuamente sobre su cabeza ${ }^{14}$. Es en este contexto en el que debemos enmarcar este resentimiento hacia nuestro personaje. Sin embargo, antes de comenzar a analizar el caso de la fama de don Francisco en relación con la Sacra Capilla de El Salvador y las manifestaciones de difamación posteriores a 1547 consideramos importante poner atención sobre una obra especialmente significativa en esta historia, el Aviso de privados y doctrina de cortesanos de fray Antonio de Guevara quien se posiciona entre la alabanza a la figura de Cobos y la llamada de atención al cortesano licencioso.

\section{Francisco de los Cobos, la virtud, la fama y el tratado de cortesanía de Fray Antonio de Guevara}

"El que es amigo de verdad es amigo de justicia,y el que es amigo de justicia es amigo de la republica, y el que es amigo de la republica es de buena conciencia, y el que es amigo de buena concienca es de buena vida, y el que es de buena vida es de buena fama, y esto dezimos para que sepan todos que al hombre que es de buena vida $y$ de buena fama no negamos que sus enemigos no le puedan cada hora ladrar; mas no les concederemos que le puedan jamas morder."

Fray Antonio de Guevara, Aviso de privados y doctrina de cortesanos.

La influencia y poder de Francisco de los Cobos propició que en su época fuese respetado y temido y que los juicios sobre su persona fuesen comedidos, tal y como ha señalado recientemente Pedro Galera ${ }^{15}$. Es más, en vida de Cobos se sucedieron las alabanzas y las dedicatorias ampulosas que lo ensalzaban, especialmente en los libros que fueron puestos bajo su protección ${ }^{16}$. Uno de estos libros, el Aviso de privados y doctrina de cortesanos [Fig. 1] de Fray Antonio de Guevara (1480-1545) publicado por primera vez en $1539^{17}$, mantiene un tono de consejo continuo a su

14 Torres Coromina, E., "Gonzalo Pérez, Francisco de los Cobos y El Lazarillo de Tormes", Libros de la Corte.es, 4, (2012), pp. 76 y ss.

15 Galera Andreu, P. A., "Francisco de los Cobos, magnificente y virtuoso", Camacho Martínez, R. y Asenjo Rubio, E. (coords. y eds.), Patronos y modelos en las relaciones entre Andalucía, Roma y el Sur de Italia, Málaga, Ministerio de Economía, Competitividad y Vicerrectorado de Investigación y Transferencia de la Universidad de Málaga, 2012, p. 90

16 No sabemos si Cobos leyó estos libros pero algunos de ellos como el de Antonio de Guevara y el de Luis de Narváez, quien se cree fue su vihuelista, tienen mucha relación con su personalidad y su estatus dentro de la Corte: Guevara, A. de, Aviso de privados y doctrina de cortesanos, Pamplina, Thomas Porralis, 1579; Narváez, L., Los seys libros del Delphin de música de cifra para tañer vihuela, Valladolid, 1538; edición Pujol, E., Madrid, Consejo Superior de Investigaciones Científicas; Instituto Español de Musicología, 1945; Osuna, F. de, Ley de amor y quarta parte del Abecedario espiritual: donde se tratan muy de rayz los misterios $y$ preguntas, y exercicios del amor, y la theologia que pertenece no menos al entendimiento que a la voluntad, harto util aun para los predicadores que dessean ver en buen romance las cosas que de si son escabrosas, Burgos, Casa de Don Juan Espinosa, 1536.

17 Desde 1529 a 1539 no tenemos ediciones del obispo de Mondoñedo. Es en 1539 cuando aparece en la imprenta de Juan de Villaquirán un volumen compuesto por la Década de Césares, la primera parte 


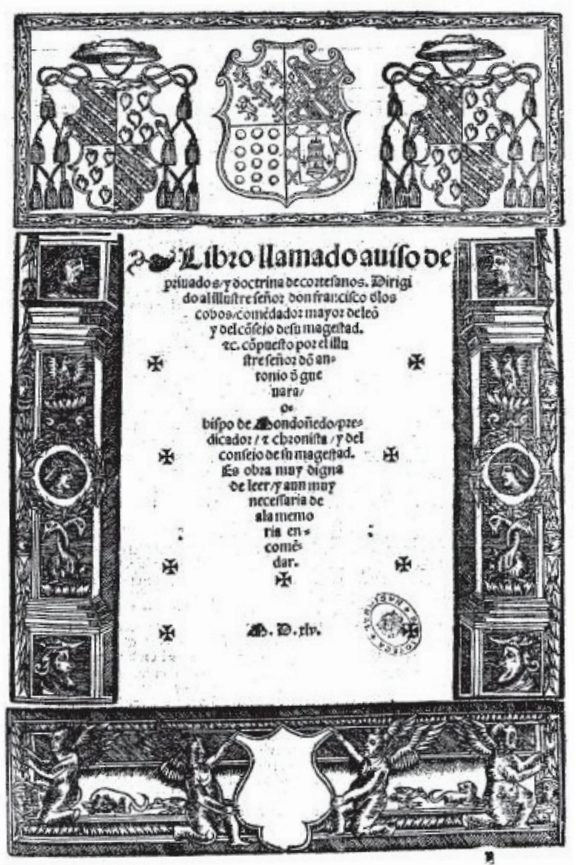

Fig. 1. Portada del libro Aviso de privados y doctrina de cortesanos de fray Antonio de Guevara impreso por Juan de Villaquirán en Valladolid en 1545. Madrid, Biblioteca Nacional de España.

protector, aunque en su pretensión también procura dar una serie de reglas generales para todo aquel que se encuentre en la corte o vaya a ella para conseguir cualquier tipo de beneficio o para resolver un pleito. Además de contener exhortaciones sobre cómo debe comportarse el cortesano a la mesa, sobre su relación con el aposentador, o cómo debe hablar al rey en una audiencia, Guevara compone un ensayo trufado de advertencias contra la corrupción y los vicios cortesanos.

El obispo de Mondoñedo fue un cortesano experimentado y en sus obras está presente la enseñanza basada en sus propias vivencias y observaciones en la corte $^{18}$, sirvan como muestra además, dos de sus escritos más conocidos: Las epístolas familiares y escogidas y el Menosprecio de corte y alabanza de aldea.

En nuestro caso, los aspectos que más nos interesan del contenido del tratado de Guevara son tres pilares que sustentan los consejos a Cobos: el privado debe su posi-

de las Epistolas familiares y escogidas, el Aviso de privados y doctrina de cortesanos, el Menosprecio de corte y alabanza de aldea y el Arte de marear lo que demuestra que Guevara pasa una década, al menos, preparando estos libros; Guevara, A. de, Obras completas, t. I, introducción de Blanco, E., Madrid, Biblioteca Castro; Turner, 1994-2004, p. XXXIII. En este artículo utilizaremos una compilación de obras del obispo de Mondoñedo que se conservan en la Biblioteca Nacional de Madrid bajo el título Las obras del illustre señor don Antonio de Guevara, obispo de Mondoñedo, predicador y chronista y del Consejo de Su Majestad, Valladolid, Juan de Villaquiran, 1545.

18 Concejo, P., Antonio de Guevara: un ensayista del siglo XVI, Madrid, Cultura Hispánica, 1985, p. 54. 
ción al mérito personal y a la virtud "la phidelidad del hombre no consiste en mucho poder, ni tener, ni valer, sino en el mucho merescer: porque la honrra o la privança o la grandeza desta vida mas vale el hombre que la meresce y no la tiene que el que la tiene y no la meresce"; la honra y por ende su fama debe mantenerla el privado para evitar caer ante las infamias de quien en la corte tenga envidia de su poder "Muy grande y muy encumbrada es la privança do os ha encumbrado fortuna, por esso os deueys señor menos que otro cortesano fiaros della [...] que los que estan en altos estados estan a caer mas subjectos"; y por último, esa fama debe quedar por escrito ante la fugacidad de la vida y la llegada de la muerte que borra todo rastro de la antigua notoriedad: "que por lo que escribo en la real chronica de vuestra inaudita privança y por lo que os sirvo como os sirvo con esta escriptura: quedara para los siglos advenideros inmortal vuestra memoria" 19 .

Muy conocida es la frase que dedica a don Francisco en el prólogo “... paresceme señor os deueys mirar y considerar quien soys, que podeys y que valeys y hallareys que entre los consiliarios soys el mayor, entre los ricos el mayor, entre los que tienen credito el mayor, entre los fortunados el mayor, entre los de vuestra patria el mayor, entre los secretarios el mayor, entre los comendadores el mayor y pues es assi, no es por cierto justo seays entre los virtuosos el menor" ${ }^{20}$. Sobre la igualdad del hombre en el nacimiento, la residencia de la nobleza en la virtud y la presencia de estas ideas en Cobos ha llamado recientemente la atención Galera Andreu en un artículo en el que liga acertadamente esta cuestión a la idea de magnificencia ${ }^{21}$. Se trata de una concepción que proviene de los tiempos de la poesía trovadoresca cortesana medieval, no de una invención del individualismo humanista del Renacimiento. Sumado a ello debemos decir que constituía más una concepción de la muerte igualadora y no una inalcanzable igualdad ante la vida ${ }^{22}$. Sin embargo, durante el siglo XVI comienzan las excepciones como es el caso de Cobos quien pudo constatar la oportunidad de medro que se abría a los secretarios reales de las cortes europeas del siglo XVI, en especial la de Carlos V que había comenzado a distanciar sus decisiones de las deliberaciones de sus Consejos, apoyándose en hombres de confianza ${ }^{23}$. En el libro de Guevara, se contempla la posibilidad del encumbramiento del cortesano exitoso como un hombre hecho a sí mismo a través de los méritos y la virtud ${ }^{24}$, en contraposición a la fortuna como ha manifestado también Galera Andreu ${ }^{25}$.

Asimismo, la cuestión de la fama y la honra era capital para el privado quien debió dotarse de expresiones de poder reconocibles por todos ante su continua exposición

19 Guevara, Las obras del illustre... op. cit., fol. 155v-157-r.

20 Íbid., fol. 66-r.

21 Galera, "Francisco de los Cobos... op. cit..

22 Huizinga, El otoño... op. cit., pp. 97-98.

23 Ruiz Fajardo, A., "La figura política de don Francisco de los Cobos", Moreno Mendoza, A. (coms.), Francisco de los Cobos y su época, Madrid, Electa, 1997, p. 13.

24 "Ya puede ser que el privado antes que viniesse a ser privado aya sido en persona no muy bien tratado, de linaje no muy subido, de patria no muy noto, de parientes no muy rico, de bienes no muy dotado y de fortuna no muy cumplido; de las quales cosas todas no solo no se deve affrentar, mas aun se debe presciar porque en mucho mas le ternan en la corte presciandose de lo que fue de antes que ensoberbesciendose de lo que es agora", Guevara, Las obras del illustre... op. cit., fol. 183-v.

25 Galera, "Francisco de los Cobos... op. cit., pp. 114-116. 
política. Sebastián de Covarrubias en su Tesoro de la Lengua nos indica: "Es fama todo aquello que de uno se divulga, ora sea bueno ora malo" ${ }^{26}$ y según Guevara la fama sin mácula es la mejor fórmula para conseguir la privanza y así, servir mejor a la República: "A mi parecer no ay en la corte tal alquimia para subir a la cumbre de la privança como es que el rey nos conozca mas por la fama que por la persona" 27 . Por ello, Guevara amonesta en repetidas ocasiones al privado sobre el peligro que corre aquel que se encuentra en tan alto estado de caer en la soberbia y el envanecimiento excesivo.

Podemos de esta forma reconocer a Cobos en las exhortaciones de Guevara contra el enriquecimiento personal y la avaricia de los cortesanos -presentes por otro lado siempre en los escritos que infaman a Cobos- así como en cuestiones como la edificación de palacios en sus lugares de origen que nunca son habitados para lo cual parece estuviera pensando en el palacio de los Cobos en Úbeda:

"Lo que mas es de espantar en los cortesanos es que labran casas en sus pueblos y nunca las van a morar, plantan sotos y huertas y nunca las quieren gozar, compran grandes heredamientos y nunca los van a ver, dieronles alla escrivanias y regimientos y nunca los van a usar, tienen alli parientes y amigos y nunca los van a conversar, por manera que quieren mas ser en la corte esclavos que en sus tierras señores. Podemos con razon dezir que son pobres en sus riquezas, huéspedes en sus casas, peregrinos en sus tierras y desterrados entre los suyos ${ }^{28}$ ".

En efecto, Cobos notó pronto como la arquitectura -por la perdurabilidad y la monumentalidad de sus productos- le daba una oportunidad para expresar su rango y posición en la sociedad de su época y declarar la importancia de su linaje ${ }^{29}$. Los edificios ligados a su nombre suelen estar emparentados a las promociones del Emperador o a las de la nobleza, en un comportamiento típico del individuo que quiere ascender en la escala social del siglo XVI, porque como escribió Huizinga "todas las formas superiores de la vida burguesa en la Edad Moderna descansan en la imitación de las formas nobles de la vida" ${ }^{30}$. En 1508, Cobos fue nombrado regidor de Úbeda, regimiento traspasado a su padre temporalmente, y en 1513 escribano del crimen de la ciudad; cargos estos de los que percibía las rentas pero de los que nunca se ocupó

26 Covarrubias Horozco, S. de, Tesoro de la Lengua Castellana o Española, ed. integral e ilustrada de Ignacio Arellano y Rafael Zafra, Madrid, Iberoamericana, 2006, p. 880.

27 Guevara, Las obras del illustre... op. cit., fol. 166-r

28 Íbid., fol. 189-v.

29 Estos son algunos ejemplos de trabajos que han recalcado esta voluntad de Cobos con respecto a la arquitectura: Barbé Coquelin de Lisle, G., "Pouvoir, mécenat, humanisme et architecture dans 1'Espagne de la Renaissance: 1'église funéraire du Salvador à Ubeda", Les groupes dominants et leur(s) discours (domaine ibérique et latino-américain). Colloque tenu à la Sorbonne les 8, 9 et 10 mars 1984, París, Université de la Sorbonne nouvelle Paris III, Servicio de Publiciones, 1984, pp. 29-39; Pérez Gil, J., "El palacio de Francisco de los Cobos en Úbeda y la notoriedad del linaje", Mágina, 10, (2002), pp. 159-174; Pérez Gil, J., El Palacio Real de Valladolid: sede de la corte de Felipe III, Valladolid, Universidad; Secretariado de publicaciones e intercambio editorial, D. L. 2006; Ruiz Calvente, M., "El castillo-palacio de la villa de Sabiote (Jaén), Estudio Histórico-Artístico", Castillos de España, 98, (1989), pp. 17-30. Tessari, C., Autocelebración y arquitectura. La familia Cobos y Molina y Andrés de Vandelvira en Úbeda, Periferia, 10, (1991), pp. 159-176.

30 Huizinga, J., El Otoño de la Edad Media, Madrid, Selecta de Revista de Occidente, 1967, p. 147. 
presencialmente. Además, su influencia sobre el poder político municipal se irá acrecentando con el paso de los años y materializándose a través de la arquitectura y el urbanismo hasta conformar una Úbeda que -en opinión de Chueca Goitica- "parece una ciudad ducal" 31 .

Volviendo al extracto de Guevara, este parece aludir a la acción del Comendador quien había acrecentado las casas familiares en su ciudad natal tras la muerte de su padre en 1530 encargando a Luis de Vega su ampliación ${ }^{32}$. Cobos desde 1518 hasta 1526 había ido adquiriendo propiedades contiguas a las familiares a las que se suman otras dos en $1531^{33}$, en un movimiento que denota que se trataba de un plan ya concebido años antes y para el cual esperó a ser heredero de la propiedad para ejecutarlo. Sin embargo, Cobos no habita el edificio hasta fechas cercanas a su muerte -si exceptuamos una breve visita del Emperador y la Emperatriz en diciembre de 1526- algo que lleva a Keniston a cuestionarse la necesidad de construir un palacio de la entidad del que hubo de ser el de los Cobos en Úbeda ${ }^{34}$. En realidad, el palacio de la familia Cobos es una representación del poderoso in absentia y guarda las proporciones dignas a la dimensión social del propietario por lo que coincidimos con Pérez Gil cuando afirma que se debe al afán de don Francisco por el cultivo de su linaje y a la proclamación de su supremacía, constituyendo la arquitectura "un alegato irrefutable de la misma y el mejor legado para sus descendientes" ${ }^{35}$.

Llegados a este punto debemos preguntarnos si realmente Antonio de Guevara se refería con sus palabras al palacio que Cobos había mandado ampliar en Úbeda o simplemente es una coincidencia. Realmente nunca podremos estar seguros de ello ya que pertenece a la intencionalidad del imaginario subjetivo del autor, pero si podemos hacernos una idea sobre la fama de la que gozaba el plan que suponemos a Cobos sobre el fomento de la arquitectura como representación de su trayectoria política y social exitosa si indagamos un poco más sobre la referencia a éstas en la literatura impresa coetánea.

\section{Francisco de los Cobos, la arquitectura y la literatura}

Otro de los palacios urbanos del Comendador -el de la Corredera de San Pablo de Valladolid [Fig. 2], obra que ocupó a Luis de Vega entre 1525 y 1528 - fue sin duda más conocido y notorio pero no más personal que el palacio ubetense. Este edificio -construido sobre una propiedad proveniente de la dote de su esposa María de Mendoza- sustituye al del conde de Benavente como residencia de los monarcas durante su estancia en la ciudad. De él dispuso ampliamente la familia imperial e incluso

31 Chueca Goitia, F., "Francisco de los Cobos: político y mecenas”, Mágina, 6, (1998/1998), p. 6.

32 Moreno Mendoza, A., "El palacio ubetense del siglo XVI. Entre la tradición medieval y la renovación clasicista", Espacio, tiempo y forma, Serie VII, 16, (2003), pp. 36-38.

33 Keniston, Francisco de los Cobos... op. cit., 145.

34 Íbid., p. 147.

35 Pérez Gil, "El palacio de Francisco de los Cobos... op. cit., p. 163. 
realizaron reformas a su configuración por cuenta propia ${ }^{36}$. Es más, Cobos pensó en su concepción cómo debía adaptarse a la etiqueta de la Casa Ducal de Borgoña por lo que Luis de Vega debió proyectar un edificio con varios espacios y patios que separasen las respectivas "casas" del rey y de la reina, así como de las que fuesen necesarias para príncipes e infantas ${ }^{37}$. Es decir, Cobos mandó edificar y costeó una fábrica que sobrepasaba sus necesidades para adecuarse a la dignidad de sus huéspedes.

Por tanto, como edificio principal de la monarquía en Valladolid, el palacio de don Francisco se convirtió en el foco de interés de la política y la sociedad mientras la corte se aposentó allí. En él se celebraron cortes y audiencias y para ello se dispuso una zona semipública que tiene como pieza vertebradora el patio principal ${ }^{38}$. Así pues, es lógico que el edificio fuese hartamente conocido y no nos debemos extrañar si encontramos una alabanza a él en el opúsculo de Cristóbal de Villalón Ingeniosa Comparación entre lo pasado y lo presente ${ }^{39}$ acompañada del calificativo de imperial:

¿Qué Memphis ó qué Pirámides se pueden comparar con el monasterio y colesio de Sant Pablo, aquí en Valladolid? ¿Y qué edificio de más excelencia que el colesio que hizo aquí el reuerendíssimo Cardenal don Pero González de Mendoza, é con las

36 Pérez Gil, El Palacio Real... op. cit., pp. 54 y 57; Redondo Cantera, Ma J., "La arquitectura de Carlos V y la intervención de Isabel de Portugal: palacios y fortalezas", Redondo Cantera, Mª J. y Zalama, M. Á. (coords.), Carlos V y las artes: Promoción artística y familia imperial, Valladolid, Junta de Castilla y León; Universidad de Valladolid, D. L. 2000, pp. 90-93.

37 Pérez Gil, El Palacio Real... op. cit., p. 57.

38 Aquí Cobos no renuncia a marcar a titularidad de su propiedad mandando esculpir una galería de bustos en unos tondos en las enjutas de los arcos del cortile labrados por Esteban Jamete. Estos representan hombres y mujeres ilustres de la Antigüedad entre los que quizás se incluyen Cobos y su esposa, así como Carlos V. Esto constituye en un espejo de moral y virtud de raigambre humanista frecuente en los palacios nobiliarios del siglo XVI y, junto a las veneras santiaguistas de los ángulos superiores del claustro, son una impronta que revela la verdadera titularidad del palacio; Pérez Gil, El Palacio Real... op. cit., p. 124. También en Andrés González, P., "Significación ideológica en el patio del Palacio Real de Valladolid", Valladolid. Historia de una ciudad, t. I, Valladolid, Ayuntamiento, 1999, pp. 55-60 aunque esta última da un excesivo protagonismo a la intervención de Cobos en la concepción del programa.

39 Villalón, C. de, Ingeniosa comparación entre lo antiguo y lo presente, Valladolid, 1539, edición de Serrano y Sanz, M., Madrid, Sociedad de Bibliófilos españoles, 1898. Villalón fue un intelectual y literato español del siglo XVI. Escritor heterogéneo, se le han atribuido obras de géneros dispares: desde novelas o tratados de filosofía y teología como El Crotalón hasta una gramática castellana. Sus obras están imbuidas del ambiente erasmista vallisoletano de la primera mitad del siglo XVI. En este pequeño libelo en forma de diálogo entre Alberto y Guillermo, Alberto defiende la superioridad de la antigüedad clásica sobre la modernidad en diversos ámbitos del saber y el conocimiento, así como la preponderancia de los personajes ilustres de la antigüedad sobre sus contemporáneos. Por el contrario, Guillermo da la réplica argumentando a favor de la contemporaneidad, heredera de una antigüedad clásica que es rectificada y perfeccionada por la modernidad. Sobre los aspectos biográficos de Cristóbal de Villalón, Serrano y Sanz sigue en el prólogo de la Ingeniosa comparación, el Viaje a Turquía atribuido a Villalón pero de dudosa veracidad. Del personaje se ocupó especialmente Narciso Alonso Cortés en dos artículos: "Acervo biográfico, Boletín de la Real Academia Española, 30, (1950), 221-224 y “Cristóbal de Villalón: algunas noticias biográficas”, Boletín de la Real Academia Española, 1, (1914), 434-448. Un análisis de sus textos se puede encontrar en Kincaid, J., J., Cristóbal de Villalón, Nueva York, Twaine Publisher, 1973. Para el análisis de su verdadera filiación erasmista, debe verse el clásico Bataillon, M., Erasmo y España: Estudios sobre la historia espiritual del siglo XVI, México, Fondo de Cultura Económica, 1980. 


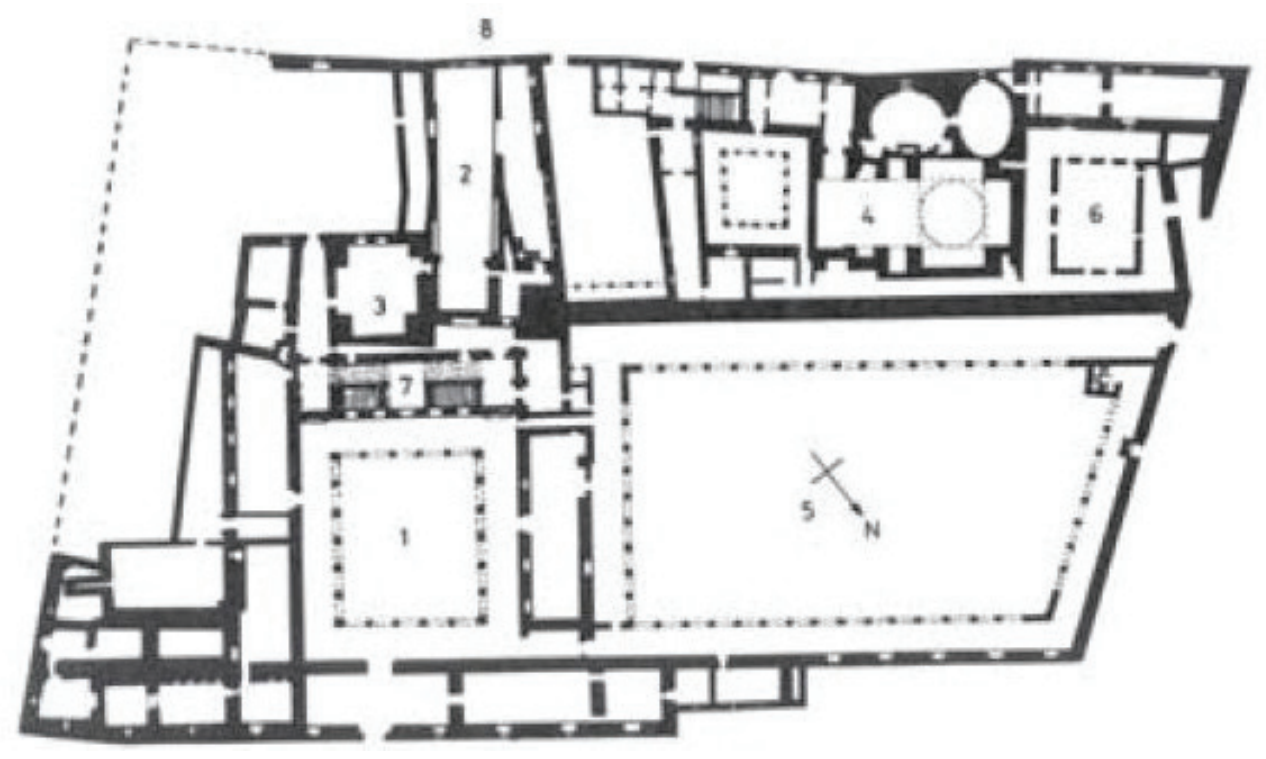

Fig. 2. Planta del Palacio Real de Valladolid, anteriormente palacio de Francisco de los Cobos y María de Mendoza; según Jesús Urrea. Con el número 1 aparece marcado el patio principal.

casas que hizo aqui el Conde de Benauente, y el palacio imperial que hizo Francisco de los Cobos? ${ }^{40}$

Asimismo, Cristóbal de Villalón nos aporta el nombre de Julio y Alejandro ${ }^{41}$ como pintores traídos de Italia por el Comendador Mayor para la decoración de este edificio, "los quales hizieron obras al gentil y antigüedad, que nunca el arte subió a tanta perfeción" ${ }^{42}$. Todo esto denota la fama que alcanzaron las promociones de Cobos y los artífices que para él trabajaron.

Pero sin duda, el edificio más personal de Cobos y por extensión de todo el linaje que estaba acrecentando es la Sacra Capilla de El Salvador de Úbeda [Fig. 3], incluida como pieza principal dentro del plan que don Francisco tenía para la ciudad en el que se contemplaba la edificación de un complejo con universidad y un con-

40 Villalón, C. de, Ingeniosa comparación... op. cit., p. 173. El subrayado es nuestro.

41 Los fresquistas Julio de Aquiles y Alejandro Mayner. Sobre el trabajo de estos pintores en España véase Almansa Moreno, J. M., Pintura mural en el Reino de Jaén, Jaén, Instituto de Estudios Giennenses, 2008; Dacos, N., "Giulio de Aquili, Andrés de Melgar et leur grotesques", Dialoghi de Storia dell'Arte, 4-5, (1997), pp. 24-25, figs. 1-5; Gómez Moreno, M., "Los pintores Julio y Alejandro y sus obras en la Casa Real de la Alhambra", Cosas granadinas de arte y arqueología, Granada, Imprenta de la Lealtad, 1916, pp. 121147; Heredia Moreno, Ma del C., "Dibujos de Alonso Berruguete, Julio de Aquiles y Andrés de Melgar en la Fundación Lázaro Galdiano", Goya, 306, (2005), pp. 132-144; López Torrijos, R., "La escuela de Rafael y el bodegón español", Archivo Español de Arte, 59, 233, (1986), pp. 32-52 y López Torrijos, R., "Los grutescos de Rafael y Udine en la pintura española: La estufa y logia de Carlos V”, Storia dell'Arte, 60, (1987), pp. 171-177.

42 Villalón, C. de, Ingeniosa comparación... op. cit., p. 170. 


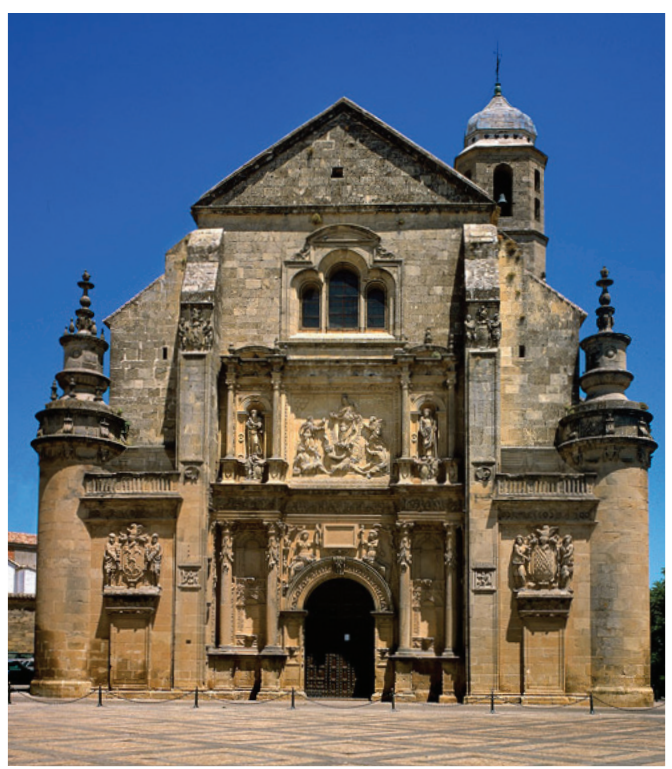

Fig. 3. Fachada de la Sacra Capilla de El Salvador (Úbeda, Jaén), presidiendo la actual plaza Vázquez de Molina. Fotografía extraída de la página web de la Fundación Ducal de Medinaceli actual propietaria del edificio. http://es.fundacionmedinaceli.org/monumento/capilla/index.aspx.

vento. La construcción de El Salvador venía a sustituir la antigua capilla familiar bajo la advocación de la Concepción comenzada a construir por su padre Diego de los Cobos desde 1525 con el apoyo de don Francisco en la parroquia de Santo Tomás -collación a la que pertenecía la familia- para lo cual compró una parcela aneja a la parroquia ${ }^{43}$.

Sin embargo, en 1534 Cobos ordena a sus representantes que adquiriesen una propiedad de la Hermandad de los Ancianos Venerables del divino Salvador y -tras alcanzar una bula de Paulo III autorizando la construcción de la capilla en 1535 así como ciertos beneficios para la construcción de la capilla y del complejo antes mencionado- se concierta en 1536 el contrato para su erección con trazas de Diego de Silóe, trasladadas a la piedra por Andrés de Vandelvira y Alonso Ruiz ${ }^{44}$. Exceptuando una breve interrupción en 1539 en la que incluso se llegó a plantear la posibilidad de trasladar las obras a su nueva adquisición de Sabiote, los trabajos se mantuvieron hasta su consagración en 1559 y a su alrededor se desplegó un nuevo polo de referencia urbanística en Úbeda. El Salvador constituye el primer hito de un proceso de apropiación por parte de una oligarquía ciudadana -Cobos y sus protegidos como el deán Ortega o su sobrino Juan Vázquez de Molina- de un terreno de propiedad

43 Keniston, Francisco de los Cobos... op. cit., p. 87; Ruiz Prieto, M., Historia de Úbeda, t. II: Historia Eclesiástica, Úbeda, [1906]; edición electrónica conmemorativa de su centenario, Úbeda, Asociación Cultural Alfredo Cazabán Laguna, 2006, pp. 89-90.

44 Galera Andreu, P. A., Andrés de Vandelvira, Madrid, Akal, 2000, p. 77. 
municipal creando una plaza cerrada por edificios palaciegos, la actual Plaza Vázquez de Molina, en una disposición donde el referente es la dicha capilla con claras analogías con procesos desarrollados en diversas ciudades italianas del Renacimiento ${ }^{45}$.

Más que los avatares de la construcción y su análisis arquitectónico, nos interesa aquí recalcar la significación que tuvo esta construcción en su época. Para ello podemos hacernos eco de la repercusión que desde mediados del siglo XVI tuvo esta construcción unida al nombre de Francisco de los Cobos. En 1558, Gonzalo Argote de Molina (1548-1596) publicaba en Sevilla su libro Nobleza del Andalucia ${ }^{46}$. En él se hace una relación de las principales casas nobiliarias del sur de Castilla apuntando su procedencia y linaje y para el caso de Úbeda refiere como casa principal la del marqués de Camarasa. Tal fue la fama de El Salvador que algunas de las obras que la adornaba como el San Juanito marmóreo atribuido a Miguel Ángel ${ }^{47}$, el retablo del altar mayor atribuido a Berruguete o las pinturas como la Piedad de Sebastiano del Piombo son los rasgos más importantes a destacar y los que, a diferencia de sus antecesores de los que no se menciona más que sus nombres, demuestran el rasgo de nobleza del Comendador a través de la ostentación de sus posesiones y de su generosidad en la dotación:

Dél [Francisco de los Cobos y Molina] desciende por varón la casa del Marqués de Camarasa y Conde de Ricla que instituyó D. Francisco de los Cobos, Comendador Mayor de León, Adelantado de Cazorla, Secretario Supremo y del Consejo del Emperador Carlos Quinto, que fue natural de esta ciudad y en ella tiene sus casas principales, y su enterramiento en la Iglesia del Salvador, que edificó, y dotó riquísimamente, con una de las más suntuosas capillas mayores que hay en toda España, y con un retablo de riquisimas figuras de talla entera de mano del famoso Berruguete, enriquecida toda la Iglesia con excelentes pinturas, despojo de los mayores pintores de aquel siglo. Donde se ve en el altar mayor un San Juan, niño de alabastro (que dize que le presentó el Senado Veneciano) joya de excelente escultura ${ }^{48}$.

45 Para este particular véase Bordés Poveda, A., "La plaza Vázquez de Molina”, Moreno Mendoza, A. y Almansa Moreno, J. M., (dirs.), Úbeda en el siglo XVI, Úbeda, El Olivo, 2002.

46 Argote de Molina, G., Nobleza de Andalucía, Sevilla, Fernando Díaz, 1558; edición facsímil, Jaén, Instituto de Estudios Gienenses, 1957. Existe asimismo facsímil alemán editada por Georg Olms Verlag en 1975 que reproduce igualmente los contenidos.

47 A pesar de que Argote de Molina hace referencia a "un San Juan, niño de alabastro (que dize que le presentó el Senado Veneciano)", el profesor Francesco Caglioti ha atribuido recientemente la escultura a Miguel Ángel Buonarroti y su procedencia como florentina. Según el profesor Caglioti, se trata del famoso San Juanito desaparecido que mencionan Giorgio Vasari y Ascanio Condivi. La obra llegaría a Úbeda como un regalo diplomático del todavía aspirante a duque de Toscana Cosimo de' Medici a Francisco de los Cobos en el verano de 1537: Caglioti, F., "Il 'San Giovannino Mediceo' di Michelangelo, da Firenze a Úbeda", Prospettiva, 145, (2013), pp. 2-81. Esta atribución viene a confirmar las primeras intuiciones de Manuel Gómez-Moreno sobre la paternidad de la escultura: Gómez-Moreno Martínez, M., "El San Juanito de el Salvador de Úbeda”, Revista Don Lope de Sosa, XVIII, 212, (1930), pp. 227-230 y “Obras de Miguel Ángel en España", Archivo Español de Arte y Arqueología, 16, 17, (1930), pp. 189-198.

48 Íbid. p. 570-571. 
En otras palabras, la publicidad de las promociones y posesiones de Cobos resultó ser muy eficaz siendo Argote de Molina consciente aún de este fenómeno once años después de la muerte del Comendador. Además, debemos añadir que esta visión será la que se transmita a los historiadores y genealogistas del Reino de Jaén posteriores a Argote de Molina, como demuestra que el fragmento dedicado a relatar la ascendencia del marquesado de Camarasa en la Historia de la antigua y continuada nobleza de la ciudad de Jaén de Bartolomé Jiménez Patón ${ }^{49}$ (15691640) se copie con total fidelidad del libro de Argote.

Pero, a pesar de que podemos constatar la existencia de recuerdos gratos de la obra de don Francisco en Úbeda, la literatura cortesana de oposición como hemos convenido anteriormente en llamarla, utilizó este edificio junto al nombre de Cobos para cargar contra los excesos del privado. En ocasiones, esta crítica se realizó de forma velada por el temor a la represión que desencadenaría para aquel que firmase el escrito como es el caso de uno de los anónimos más famosos de la literatura $E l$ Lazarillo de Tormes. En otras ocasiones, la distancia del escritor de la corte Habsburgo permitió que el nombre de Cobos apareciese explícitamente en las invectivas como es el caso del Diálogo de la preparación de la muerte de Pedro de Navarra.

Si realmente detrás de la figura del Arcipreste de San Salvador en el Lazarillo de Tormes se encuentra la persona de Francisco de los Cobos -como ha manifestado recientemente Torres Corominas ${ }^{50}$ - nos encontraríamos de nuevo con un ejemplo de escrito difamatorio contra Cobos que lo relaciona directamente con la fundación de su capilla. Para el autor, la figura de Lázaro de Tormes no es otra que Gonzalo Pérez, uno de los beneficiados por Cobos como servidor personal que asciende en la corte gracias al favor de su protector. La nueva lectura del Lazarillo de Tormes que se propone es la de una sátira anticortesana escrita por algún miembro del bando opositor a la facción que encabeza Cobos y que ve en Gonzalo Pérez una continuación del la línea política que representaba el Comendador. En la novela se retratan los oscuros procedimientos "ese universo áulico hipócrita y falaz, mundano y laberíntico, carente de Dios y de moral" que es la corte de Carlos V -recordemos la advertencias de Guevara- a cambio de la adopción de la distinción, usos y maneras del cortesano y de poder asegurar la existencia. Torres Corominas, apoyándose en Brenes, da pruebas sobre la posibilidad de que ese Arcipreste de San Salvador escondiese la figura de Francisco de los Cobos. Entre otras, el mismo título del personaje -inexistente en su época- y la coincidencia con la advocación de la iglesia-panteón del Comendador ${ }^{51}$.

Por otro lado, el Diálogo de la preparación de la muerte es una obra escrita por Pedro de Navarra, obispo de Comenge y miembro del Consejo Supremo del Rey

49 Jiménez Patón, B., Historia de la antigua y continuada nobleza de la ciudad de Jaén, Jaén, Pedro de la Cuesta, 1628, fol. $183 \mathrm{r}$.

50 Torres Corominas, "Gonzalo Pérez..., op. cit. Torres Coromina cita a Dalais Brenes Carrillo como el estudioso que primero identificó a ambos personajes como Gonzalo Pérez y Francisco de los Cobos en sus artículos: Brenes Carrillo, D., "Lazarillo de Tormes: Roman à clef", Hispania 69, 2, (1986), pp. 234-243; “Lazarillo, Vlixea y Anón”, Boletín de la Biblioteca Menéndez Pelayo, 63, (1987), pp. 57-104 y “¿Quién es V. M. en Lazarillo de Tormes?”, Boletín de la Biblioteca Menéndez Pelayo, 68, (1992), pp. 73-88.

51 Torres Corominas, "Gonzalo Pérez... op. cit., pp. 89-90 y 91 y ss. 
de Francia ${ }^{52}$. Estructurada en forma de diálogo entre Basilio y Cipriano, Pedro de Navarra dedicó a Francisco de Eraso esta obra de corte erasmista en la que Cobos era el protagonista "Y porque el suiecto dela disputa fue el principal privado del Caesar Francisco de los Cobos, a quien V.M. a sucedido en officio y pribança, me parescio que no era iusto, que yo dirigiesse a otro mi obra..." ${ }^{53}$. Basilio encarna a un Francisco de los Cobos codicioso y prepotente que siempre había obrado a favor de la obtención de riqueza personal y fama. En la trama Cobos no sigue los deberes del buen cristiano ${ }^{54}$ y es reprendido por Cipriano quien le muestra el suplicio que le acarrearán sus actos tras la muerte igualadora. Ante la descripción de las torturas del infierno, Cobos acaba arrepintiéndose:

"O sieruo de Dios Cipriano, yo confiesso mi ceguedad, mi pertinancia, mi condenación, mi desuentura, confiesso mi olvido de Dios, mi acuerdo de la auaricia, mi descuydo de la humildad, y mi solicitud en la soberuia, mi total ocupación en la felicidad humana: y mi ningún exercicio en la acquisicion de la gloria diuina. Confiesso que naci pobre plebeyo, y iactome de rico cortesano, naci sieruo para seruir: y hago me seruir a quien debo seruicio, naci en el estado de solo hijo de algo: y biuo en la cumbre de la caualleria, ninguno de mis pasados llego a diez criados para seruirse, e yo e diez mil para mi seruicio y probecho, Solia tener a mucho el vestido de buen paño e ahora desdeño [...] confiesso finalmente a ti mi Dios veynte años de olvido en tu seruivcio, y mi sacrificio, porque si mi lengua te adoraba, mi coraçon lexos estaba de $t i$, y ansi ni tu me oyas (por ser yo pecador) ni yo me seruia con mis limosnas ni oraciones, por no estar en tu gracia, de arte,que por seruir al mundo, ofendi a ti mi Dios en todo este tiempo ${ }^{55}$."

Cobos-Basilio intenta comprar el perdón de Cipriano a través de dinero o bienes materiales de lujo:

...suplico te me remedies con la confesión: porque yo aun no te tengo tan olvidado: que alla tengo para ti, un rico relox de oro, que me traxeron de Flandes, con diez dozenas de martas zeuellinas, que me enviaron de Polonia, tanbien te cabran un par de frisones conque vayas a caça en tu canonicato... ${ }^{56}$

52 Navarra, P. de, Diálogos muy subtiles y nobtables: Diálogos de la preparación de la muerte. Dictados por el Ilustrissimo Reuerendissimo Señor Don Pedro de Nauarra Obispo $9^{\circ}$ de Comenge y del consejo supremo del Christianissimo Rey de Francia. Dirigidos al muy magnifico señor Francisco de Erasso primer secretario y del consejo secreto del Rey Católico de España, Zaragoza, Juan Millan, 1567. Hemos consultado esta edición completa de los Diálogos muy subtiles y nobtables que se encuentra en la Biblioteca Nacional de Madrid. También hay otra incompleta que solo incluye uno de los diálogos, en concreto De qual debe ser el chronista del príncipe. Agradecemos a Pedro Antonio Galera Andreu la información sobre la existencia de este libro.

53 Íbid. fol. $43 \mathrm{r}$.

54 Íbid. fol. $46 \mathrm{r}$.

55 Íbid. fol. 47 v-r.

56 Íbid. fol. 53 v. Este pasaje junto a otro en el que Cobos-Basilio nombra otras riquezas nos permiten recomponer cuales eran los bienes muebles más preciados por la nobleza del siglo XVI: "De que me seruiran las martas de alemaña? Las pinturas y antiguallas de Ytalia? La tapiceria de Flandes? Los brocados de Venecia. 
Incluso llega a ofrecer ciertas acciones pías como casamientos de huérfanas, limosnas para pobres o dotación de hospitales (en referencia al acuerdo adoptado con la Cofradía del Hospital de Honrados Viejos de Úbeda para que le donase el terreno sobre el que construyó la Sacra Capilla de El Salvador de Úbeda a cambio de algunos arreglos en el hospital, pensiones e indulgencias papales). Pero a pesar de los ofrecimientos, Cobos-Basilio encuentra la negativa de Cipriano quién considera que esa no es la vía del pecador para alcanzar la salvación; ni siquiera sus fundaciones religiosas le remediarán por estar hechas en pecado, en la búsqueda de la gloria personal y con las rentas de otros territorios y posesiones ${ }^{57}$.

Cobos-Basilio también mantiene un diálogo ficticio con la muerte en el que esta reprende la suntuosidad y lujo de su capilla- panteón, construida con los tributos de los trabajadores de otras parroquias desviados por el Papa a través de bulas para la erección de la Sacra Capilla de El Salvador. Esta aparece ya como una constante hasta el final del diálogo como solía ser habitual en la crítica a este tipo de fundaciones religiosas en las diatribas de los reformadores erasmistas ${ }^{58}$. Este edificio, vanagloria de la vida mundana y del fundador, está construido para perpetuar la fama personal del Comendador ${ }^{59}$, algo que la muerte no perdona. Incluso reconoce Cobos-Basilio el método empleado para conseguir estas bulas a través de enviados en Roma que engañaban al Sumo Pontífice sobre la verdadera intención que perseguía Cobos ${ }^{60}$. Al final del diálogo, don Francisco termina por renunciar a la gloria terrenal y a las riquezas materiales y pide disculpas por todos sus pecados y su vida alejada de la religión.

\section{Conclusiones}

Los enfrentamientos por el poder en la corte de Carlos $\mathrm{V}$ afectaron directamente a Francisco de los Cobos como el personaje más influyente ante el Emperador en la década de los años treinta del siglo XVI. Estos choques tendrán como resultado diatribas en la literatura impresa de su tiempo que gracias a la imprenta se convirtió en

Las sedas de Genoua, el oro de Calicut, las perlas de Guinea, los lienços de Portugal, y los guantes de Canaria, sino de nueuos tormentos para el cuerpo y de secos leños para el alma." Íbid. Fol. 74 v.

57 Íbid. fol. $52 \mathrm{v}-\mathrm{r}$ y $53 \mathrm{v}$

58 Esta crítica a la innecesaria monumentalidad y riqueza de las fundaciones religiosas aparece en otros diálogos erasmistas como el Viaje de Turquía de Cristóbal de Villalón o El diálogo de las cosas acaecidas en Roma de Alfonso de Valdés en el cual puede leerse: "Piensa el mercader, después que mal o bien ha allegado a una infinitud de dineros, que todos cuantos males ha hecho, y aún hará, le serán perdonados si edificase una iglesia o un monesterio, o si diere una lámpara, o un cáliz o alguna otra cosa semejante a alguna iglesia o monesterio, y no solamente en esto se engaña, pareciéndole que hace por su servicio lo que las más veces se hace por un Fausto o por una vana gloria mundana, como manifiestan las armas que cada uno pone en lo que da o en lo que edifica; mas, fiándose en esto, le parece que no ha más menester para vivir como cristiano, y seyendo éste un grandísimo error, no tienen vergüenza de admitirlo los que dello hacen su provecho, no mirando la injuria que en ello se hace a la religión critiana". Valdés, A. de, Diálogo de las cosas acaecidas en Roma, ed. de Rosa Navarro Durán, Madrid, Cátedra, 2011, p. 177.

59 Navarra, Diálogos de la preparación... op. cit., fol. 84 r y 85 v-r.

60 Íbid. fol. 85-v. 
un vocero fundamental a la hora de ampliar el alcance del juego de las infamias y las maledicencias cortesanas.

Ante esta situación, creemos que Cobos llevó a cabo un programa de dignificación personal ante los ataques que sufría desde dentro de la Corte contra su posición privilegiada ante el Emperador, los cuales inevitablemente se referían a su persona, consistente en el uso de esa misma arma en beneficio propio. Cobos intenta poner un contrapeso a la difamación y es en esta necesidad en la que fray Antonio de Guevara aprovecha para poner su escrito bajo buen reguardo. Sin embargo, el obispo de Mondoñedo, fiel a su estilo, no duda en reprender a Cobos en asuntos de moral construyendo un alegato en forma de memento mori que antecede a las críticas póstumas al Comendador tras su muerte en 1547.

Asimismo, es durante las décadas treinta y cuarenta del siglo XVI -en las que Cobos es encumbrado a la cima de su poder- cuando don Francisco desarrolla sus proyectos arquitectónicos más ambiciosos teniendo como hito fundamental su morada para la muerte, la Sacra Capilla de El Salvador. Ya sea en forma de alabanza o en forma de crítica hay indicios de que las construcciones de Cobos gozaron de una amplia resonancia unidas a su nombre lo que demuestra que la intención del Comendador de apoyarse en sus promociones edilicias para representar la importancia de su nombre y linaje funcionaron. El ejemplo más significativo será, como hemos dicho, la Sacra Capilla de El Salvador de Úbeda, ampliamente conocida en el entorno cortesano y utilizada por la facción de oposición como diana sobre la cual lanzar las diatribas que infamen al Comendador. Estas invectivas cobran mayor importancia tras su muerte, pero aún así debemos notar cómo sus detractores aún deben esconderse en el anonimato o en la lejanía de la influencia de los seguidores del Comendador.

Las críticas que se efectúan a Cobos en relación a su imponente iglesia-panteón son las propias de la corriente de pensamiento erasmista: falsa voluntad piadosa bajo la que se esconde la vanagloria personal, olvido de la religión, corrupción y excesiva soberbia. Es por eso por lo que se utilice la construcción que representa la obsesión de Cobos ante la muerte para castigar eternamente el alma de un personaje que había llegado al final de sus días en el poder sin que sus enemigos hubiesen podido hacerle caer. 